\title{
Occupational exposures and mortality from cardiovascular disease among women textile workers in Shanghai, China
}

\author{
Lisa G. Gallagher, DSc, MPH ${ }^{1}$, Roberta M Ray, MS ${ }^{2}$, Wenjin Li, MD, PhD, MPH ${ }^{2}$, Bruce M. \\ Psaty, MD, PhD $3,4,5,6,7$, Dao Li Gao, MD, MPH ${ }^{8}$, David B. Thomas, MD, DrPH ${ }^{2,4}$, and Harvey \\ Checkoway, PhD,MPH ${ }^{1,4}$ \\ ${ }^{1}$ Department of Environmental and Occupational Health Sciences, University of Washington, \\ Seattle, WA \\ 2 Public Health Sciences Division, Fred Hutchinson Cancer Research Center, Seattle, WA \\ ${ }^{3}$ Cardiovascular Health Research Unit, University of Washington, Seattle, WA \\ ${ }^{4}$ Department of Epidemiology, University of Washington, Seattle, WA \\ ${ }^{5}$ Department of Medicine, University of Washington, Seattle, WA \\ ${ }^{6}$ Department of Health Services, University of Washington, Seattle, WA \\ ${ }^{7}$ Group Health Research Institute, Group Health Cooperative, Seattle, WA \\ ${ }^{8}$ Zhong Shan Hospital Cancer Center, Shanghai, China
}

\section{Abstract}

Background-Exposure to textile fiber dusts, like particulate air pollution, may be associated with cardiovascular disease (CVD) mortality. Bacterial endotoxin, a potent inflammagen found in cotton dust, may be a specific risk factor.

\begin{abstract}
Methods-Female textile workers $(\mathrm{N}=267,400)$ in Shanghai, China were followed for CVD mortality (1989-2000). Factory exposures were approximated by sector classifications based on materials and processes. Quantitative endotoxin and cotton dust measures were available for a subcohort $(\mathrm{n}=3,188)$. Cox proportional hazards modeling was used to estimate hazard ratios $(\mathrm{HR})$ and $95 \%$ confidence interval $(\mathrm{CI})$.
\end{abstract}

Results-Slightly elevated mortality risk for the cotton sector was seen for ischemic stroke $(\mathrm{HR}=1.12,95 \% \mathrm{CI} 0.97-1.31)$ and hemorrhagic stroke (HR=1.12, 95\%CI 1.02-1.23). Similar hemorrhagic stroke mortality risk was observed in high dust sectors (HR=1.12, 95\%CI 1.02-1.24). No association was observed for ischemic heart disease.

Conclusions-Exposures in textile factories may have contributed to CVD mortality among this cohort. The specific components of these exposures that may be harmful are not clear and should be further investigated.

\section{Keywords}

Cardiovascular diseases; stroke; mortality; endotoxin; China

Corresponding Author: Lisa G. Gallagher, University of Washington, Department of Environmental and Occupational Health Sciences, Box 357234, Seattle, WA 98195-7234, Phone: (206) 616-1109, Fax: (206) 685-3990, lgallag@u.washington.edu.

Conflict of Interest: None 


\section{Introduction}

Cardiovascular diseases (CVD), such as heart disease and stroke, are leading causes of morbidity and mortality worldwide [Bonow, et al. 2002], with several well-established risk factors, including hypertension, lipid abnormalities, and smoking [Ueshima, et al. 2008]. Environmental factors, such as particulate air pollution, have also been implicated in the increasing risk of cardiovascular events from short and long-term exposure [Brook, et al. 2010, Dockery, et al. 1993, Miller, et al. 2007]. Similar particulate exposures can occur in the workplace, as well as exposures to metals, solvents, and pollutant gases that have also been shown to increase the incidence of CVD [Bhatnagar 2006, Sjogren, et al. 2012].

Many of these exposures can be found in the textile industry, including fiber dusts and endotoxin, a component of gram-negative bacteria. Endotoxin is widespread in the cotton textile industry and in other industrial and agricultural settings, and may trigger or accelerate atherosclerosis (thickening of arterial walls) either by acting as a source of inflammation or other mechanisms [Stoll, et al. 2004]. Increased plasma concentrations of fibrinogen may occur from inhalation of organic dusts and are considered a possible risk factor for ischemic heart disease [Sjögren, et al. 2003]. However, epidemiological evidence is limited to observations of slightly increased cardiovascular disease mortality in agricultural workers in crop and livestock production [Fleming, et al. 2003, Lee, et al. 2002, Sjögren, et al. 2003]. Other workplace factors, such as physical inactivity at work, stress, noise, vibration, extreme temperature, and shift work, may also affect CVD risk [Kawachi, et al. 1995, Kristensen 1989, Price 2004]. These chemical or physical exposures may contribute to cardiovascular disease by promoting or modifying other major risk factors, such as hypertension, hypercholesterolemia, or diabetes [Bhatnagar 2006].

Most occupational studies of cardiovascular disease have been restricted to men and do not adequately address the possible effects of workplace exposures among women. There are few opportunities to examine large cohorts of women with one or more potentially CVDrelated occupational exposures, with the notable exception of shift work in nurses [Steenland, et al. 2000]. Otherwise, CVD has been studied in working women primarily to account for associations with job strain, stress and balance of work and home life [Price 2004, Steenland, et al. 2000]. While traditionally employed in service sectors in many regions, employment of women in other sectors of the labor force has increased steadily worldwide, especially in the relatively newly industrialized states of Asia, thus causing potentially harmful new occupational exposures to women [Kane, et al. 1999]. In these regions, the economic expansion and success in export-oriented light industries, such as electronics or textiles, are thought to be largely due to the large pool of women workers [Kane, et al. 1999]. Research on CVD is limited in these industries especially among female workers. This study examined cardiovascular mortality in a large cohort of female workers in the textile industry in Shanghai, China, in relation to occupational exposures to dusts and chemicals.

\section{Materials and Methods}

\section{Study Population}

Female textile workers were initially enrolled in a randomized trial of breast selfexamination from 526 textile factories in Shanghai [Thomas, et al. 2002, Thomas, et al. 1997]. From 1989 until 2000, this cohort was followed for cancer incidence and vital status. The cohort included 267,400 women who were active or retired as of 1989-1991. At enrollment, demographic information, lifestyle factors, and reproductive history were collected by questionnaires administered by factory medical workers. Information about each factory in the study was collected by trained local industrial hygienists. For a series of 
nested case-cohort studies of cancer, a comparison subcohort of 3,188 women was randomly selected from the entire cohort. Subject job assignments and employment dates were determined from factory personnel records (80\%), factory supervisors or co-workers (12\%) and in-person or family member interviews (8\%) [Wernli, et al. 2006].

\section{Exposure Definition}

Each factory was assigned to an industry sector based on manufacturing materials and processes. The sectors were: (1) cotton spinning, weaving, and knitting (SWK); (2) silk SWK; (3) wool SWK; (4) synthetic fiber SWK; (5) mixed fiber SWK; (6) garment assembly and sewing; (7) bleaching/dyeing/printing; (8) machine and manufacturing; (9) combined; and (10) other services [Wernli, et al. 2006]. Sectors were designated as "combined" if the factory had multiple production lines that could be assigned with two or more sector codes. The sector of the factory workers reported at the time of enrollment (baseline) was used as a proxy for prior exposures. The "baseline factory" was defined as the current factory for active employees at the time of interview, and the last place worked for women who were retired at interview. The sectors were further classified with respect to exposures of interest for which other literature suggests associations with CVD risks. Working in one of the sectors known to have high dust levels (cotton, wool, synthetic and mixed fiber SWK) was considered a proxy for exposure to particulate matter. Since endotoxin is a known contaminant of cotton dust, working in the cotton SWK sector was analyzed as a proxy for endotoxin exposure. Additionally, sectors where elevated mortality rates were observed in the current study were analyzed further.

For women in the subcohort, quantitative endotoxin and cotton dust exposure data were assessed and validated, and have been described in detail elsewhere [Astrakianakis, et al. 2006]. Briefly, job and time period-specific cotton dust exposure levels were determined based on 2,400 historic cotton dust measurements made by Chinese factory inspectors in 56 cotton factories between 1975 and 1999. Dust estimates were converted to endotoxin estimates using measurements made in three Shanghai factories in 2002 [Astrakianakis, et al. 2006] and job-specific endotoxin surveys [Christiani, et al. 1993, Christiani, et al. 1999, Kennedy, et al. 1987, Olenchock, et al. 1983]. Exposure estimates for all jobs that each woman held throughout the textile industry work history were summed to obtain cumulative exposure estimates for both types of exposures.

\section{Outcome Definition}

Cause of death information was collected from the Shanghai Textile Industry Bureau's Tumor and Death Registry. CVD outcomes listed as one or more causes of death by International Classification of Diseases, Ninth Revision (ICD-9) code were included in this analysis. These outcomes included ischemic heart disease mortality (ICD-9 codes 410-414), ischemic stroke mortality (434), and mortality from intracerebral hemorrhage (431). Personyears were accumulated from the date of the baseline questionnaire until death, severance of ties with the Shanghai Textile Industry Bureau (STIB), or end of follow-up (December 31, 2000) whichever event occurred first.

\section{Data Analysis}

Age-adjusted mortality rates for the entire cohort and for each textile sector were computed for each CVD cause of death by direct methods using the 2000 World Standard Population as the standardizing population in 5 year age categories [Parkin 1997, Waterhouse, et al. 1976]. Mortality rates were also calculated separately by smoking status (ever/never).

Sectors with selected exposures of concern were determined from a priori hypotheses (particulate matter, endotoxin) and by observing elevated sector-specific mortality rates in 
the current study. These sectors were compared to the remainder of the cohort using Cox proportional hazards modeling to calculate hazard ratios and associated $95 \%$ confidence intervals, adjusted for age at baseline (continuous) and smoking (ever/never).

Individual level quantitative exposure data for endotoxin and cotton dust were only available for the subcohort $(n=3,188)$ that had been selected as a comparison group for prior analyses of cancer outcomes, not for all CVD deaths. As such, only a subset of the CVD deaths in the larger cohort occurred among members of the subcohort. To allow our findings in the sampled subcohort to be representative of the entire cohort, we calculated weights equal to the inverse of sampling fractions determined by age group and CVD death outcome. We included the natural logarithm of the weights as an offset term in a Cox proportional hazards model that used risk sets created for time-varying covariates. Workers with potential occupational endotoxin exposures from jobs in non-cotton factories were not quantified (early stage wool processing, metal machining, or sanitation) and were excluded from the analysis of endotoxin exposure (149 subcohort members). The categories of exposure were based on quartiles of subjects who died from stroke and whose exposure was assessed at greater than zero. Trend tests were conducted using the median value of the distribution within exposure categories. Analyses were adjusted for age at baseline (continuous) and smoking (ever/never).

All statistical analyses were completed in SAS 9.2 (SAS Institute, Cary, NC).

The study was approved by Institutional Review Boards at the University of Washington, the Fred Hutchinson Cancer Research Center, Seattle, WA, and the Station for the Prevention and Treatment of Cancer of the Shanghai Textile Industry Bureau at Zhong Shan Hospital, Shanghai, China.

\section{Results}

\section{Demographic, Lifestyle and Occupational Factors}

A total of 2,565,433 person-years of follow-up were accumulated by the cohort of 267,400 women from enrollment until the end of vital status follow-up in 2000. The median age at enrollment was 43 years; women ranged in age from 30 to over 60 years and 37\% were retired at interview (Table I). Less than 3\% of women had ever smoked for more than 6 months, and this percentage did not vary widely between textile sectors, ranging from $1.4 \%$ to $3.6 \%$. Smoking varied markedly by age as result of the social changes in China over these women's lifetimes (median age: never smoked, 42 years; ever smoked, 59 years). Women born prior to 1936 were more likely to have ever smoked cigarettes $(81.7 \%)$. Women in the cohort worked in a variety of textile factory sectors, with the largest number of women employed by the cotton SWK sector (32.3\%) at baseline.

\section{Rate of CVD Mortality}

There were 4,349 deaths listed with one or more causes from cardiovascular outcomes (ICD-9 390-459). Among the 2,776 deaths from stroke (ICD-9 430-438), 699 were from ischemic stroke (ICD-9 434) and 1,815 were from hemorrhagic stroke (ICD-9 431) (the remainder were of unknown or other type). 494 deaths were from ischemic heart disease (ICD-9 410-414). There were 38 women in the cohort with missing smoking status variables who were excluded from analyses including that variable. The age-standardized mortality rate for the entire cohort was 6.9 per 100,000 for ischemic heart disease, 37.9 per 100,000 for all strokes ( 8.7 for ischemic stroke and 24.8 for hemorrhagic stroke) over the follow-up period. In the entire cohort, mortality rates were lower in the women who never smoked and higher in women who smoked. For ischemic heart disease, mortality rates were 6.5 per 100,000 for never smokers and 20.6 per 100,000 for ever smoked. For ischemic stroke, 
mortality rates were 8.3 per 100,000 for never smoked and 15.9 per 100,000 for ever smoked. For hemorrhagic stroke, mortality rates were 23.9 per 100,000 for never smoked and 92.9 per 100,000 for ever smoked.

Age-standardized mortality rates for all cardiovascular outcomes combined were highest for synthetic SWK (143.2 per 100,000), bleaching/dyeing/printing (74.1), and cotton SWK (71.6), while the other sectors were marginally lower (46.3-64.9) with a particularly low rate for other services (27.0). As shown in Table II, mortality rates for ischemic heart disease in the cohort were highest for the combined sector (factories with multiple production lines), wool SWK and cotton SWK sectors; whereas the remaining sectors had similar rates. For all types of stroke combined, the synthetic SWK and bleaching/dyeing/printing had the highest rates (data not shown). The highest rates for ischemic stroke were in the synthetic SWK and bleaching/dyeing/printing sectors. Mortality rates for hemorrhagic stroke were slightly higher in cotton SWK than other sectors, with the exception of other services, which had a much lower rate. Further examination revealed that several of these comparatively high mortality rates were influenced by the combination of one death and small numbers of person-years in the lowest age category (30-34 years). Excluding these deaths $(n=3)$ changes the ischemic heart disease mortality rate of the combined sector from 10.13 to 4.58 , the ischemic stroke mortality rate in the bleaching/dyeing/printing sector from 26.73 to 6.92 and in the synthetic SWK sector from 50.63 to 5.35 . Similarly to the whole cohort, slightly lower rates in the women who never smoked and higher rates in women who smoked were seen in each sector (data not shown). The elevated mortality rates in these sectors (synthetic SWK and bleaching/dyeing/printing sectors) were analyzed further using a Cox proportional hazard model to compare them to the remainder of the cohort (results given below).

\section{Risk of CVD Mortality for Selected Textile Sectors}

Exposure to endotoxin in cotton factories was first approximated by comparing women who worked in the cotton SWK sector at baseline with the remainder of the cohort (Table III). Slightly elevated risks, of borderline statistical significance, were observed for ischemic and hemorrhagic stroke. Results were very similar when workers in other sectors with potential for endotoxin exposure that was not quantified (wool SWK and machine manufacturing) were excluded from the referent group.

Exposure to particulate matter was approximated by grouping the sectors known to have high dust levels (cotton, wool, synthetic and mixed fiber SWK) and comparing them to the remainder of the cohort (Table III). A slightly elevated risk for hemorrhagic stroke mortality was observed, but no appreciable association for other CVD mortality outcomes was seen. Given the overlap with the endotoxin analysis, the cotton SWK sector was excluded to attempt to independently assess dust exposure and limit to non-cotton dusts. This resulted in null associations for all three CVD outcomes.

When compared to the remainder of the cohort, there was little to no increased risk for any of the three outcomes considered in relation to the most likely exposures (solvents and carbon disulfide) in the two sectors that showed elevated ischemic stroke mortality rates (synthetic SWK and bleaching/dyeing/printing sectors) (Table III). Excluding workers in the cotton SWK from the referent group did not appreciably change these results.

The results were only minimally changed when analyses were restricted to non-smokers (data not shown).

\section{Risk of CVD Mortality and Exposure to Endotoxin and Cotton Dust}

There were 13 deaths from ischemic heart disease and 60 deaths from stroke (all types) among the workers in the subcohort with quantitative measures of exposure to endotoxin 
and cotton dust. Ischemic heart disease deaths were too few for meaningful analysis. There was a possible increase in risk in all strokes combined in women in the highest exposure category, but no evidence of an increase in risk in the other categories (Table IV). Results were similar when exposures were lagged by 5,10 and 15 years (data not shown). When restricted from all stroke types to only hemorrhagic stroke $(n=44)$, the results were similar overall, but with a smaller excess risk in the highest exposure category $(\mathrm{HR}=1.22,95 \% \mathrm{CI}$ 0.48-3.08). The higher risk observed for all strokes may be due to other stroke types (primarily ischemic), although overall the numbers are very small. There is high correlation between the measures of exposure to endotoxin and cotton dust. A slightly increased risk of stroke mortality was also seen with higher cotton dust exposures. However, it was at a lower magnitude than what was observed for endotoxin exposure at the highest exposure category (Table IV).

\section{Discussion}

Mortality from cardiovascular outcomes varied substantially among textile sectors. There was some suggestion that employment in the cotton SWK sector may be associated with an increased risk for stroke mortality compared to the remainder of the cohort. The subcohort analyses suggest that endotoxin exposures found in this sector may contribute, but the estimate was based on small numbers, confined to the highest exposure stratum, and there was no evidence of a trend. No strong associations were found for ischemic heart disease mortality and textile industry exposures in this cohort.

Other studies of mortality from cardiovascular disease in textile workers have generally reported fewer than expected numbers of deaths [Berry, et al. 1981, Fritschi, et al. 2004, Hodgson, et al. 1990, Koskela, et al. 1990, Merchant, et al. 1981] but there are some exceptions. Increased ischemic heart disease mortality was observed in textile workers in the UK, particularly spinners and weavers, and in workers in Sweden [Sjögren, et al. 2011, Zanardi, et al. 2011]. Increased hospitalization for ischemic heart disease was seen among workers self-employed in textile industry [Tuchsen, et al. 1992]. Two studies found some evidence of slightly increased CVD mortality for women in the textile industry [Fritschi, et al. 2004, Merchant, et al. 1981], but a meta-analysis found fewer deaths than expected from circulatory disease among female cotton textile workers ( $\mathrm{SMR}=0.94,95 \% \mathrm{CI} 0.81,1.06$ ) [ $\mathrm{Su}$, et al. 2004].

Jobs in the cotton SWK and wool SWK sectors commonly include exposure to fiber dusts, considered similar to particulate exposures. Short and long-term exposures to ambient particulate matter have been shown consistently to increase risk of cardiovascular events in epidemiological studies of community air pollution [Brook, et al. 2010]. Pathogenetic mechanisms are uncertain, but inhaling small particles may induce changes in blood pressure, inflammation, autonomic balance, and blood coagulation [Bhatnagar 2006]. Studies on the effects of particulate air pollution on mortality have shown consistent risk elevations in cohorts of American men and women, as well as specifically in postmenopausal women [Health Effects Institute 2000, Miller, et al. 2007]. In China, similar studies have been restricted to monitored air pollutants, which are limited but often include total suspended particulates; the findings have been generally consistent with studies in the US [Chen, et al. 2004].

Endotoxin exposure is widespread in the textile industry, particularly in cotton factories, and may potentially contribute to an inflammatory response. This may contribute to atherosclerosis [Stoll, et al. 2004], and the disruption of blood flow may contribute to the occurrence of strokes. To date, the epidemiological evidence for an association of endotoxin with CVD is limited to slightly increased cardiovascular disease mortality observed in 
agricultural workers in crop and livestock production, likely exposed to organic dusts containing endotoxin [Fleming, et al. 2003, Lee, et al. 2002, Sjögren, et al. 2003].

Prevalent exposures in the synthetic sector were reportedly synthetic fiber dusts, solvents, resins and dyes. Similarly, in the bleaching/dyeing/printing sectors a wide variety of expected chemicals include bleaching agents, solvents, acids, bases, caustics, dye chemicals, inks, and resins [Wernli, et al. 2006]. There is some evidence of CVD effects from one agent in particular, carbon disulfide, used routinely production of rayon, a synthetic material [Gelbke, et al. 2009]. However, it should be noted that elevated stroke mortality rates were mainly due to the effect of a small number of deaths in lower age groups. Also, when these sectors were compared to the remainder of the cohort, no increased risk was observed.

Several other exposures in the textile industry that we could not assess might also have contributed to CVD risks. Sedentary work is associated with CVD as is irregular heavy physical exertion, and although results are somewhat inconsistent, studies on noise exposure indicate elevations in blood pressure which could contribute to CVD [Price 2004]. Shift work has been found to increase risk of coronary heart disease and stroke [Brown, et al. 2009, Kawachi, et al. 1995]. Unfortunately, with the exception of endotoxin and cotton dust, quantitative assessment of specific occupational exposures (e.g., other fiber dusts, solvents) for the subcohort was not possible due to the low frequency of these exposures among the few stroke deaths that occurred in the subcohort.

This study had several strengths, including the large accumulation of person-time and ability to examine a variety of occupational exposures for CVD which have not been extensively studied in female workers. Also, similarities in CVD mortality rates to the general population of Shanghai indicate follow-up was likely successful in identifying most CVD deaths that occurred in the cohort; although a possible healthy worker effect may exist for stroke. Available mortality rates for Shanghai women ages 35-64 years from 1987-1993 [Wu, et al. 2001] used the same population and method to age standardize as this analysis. They report annual mortality rates for coronary events from 1.0 to 3.0 per 100,000 similar to the cohort $(4.3$ per 100,000$)$ for women of the same age. For stroke, Shanghai women had an annual mortality rate of 29.5 to 43.3 per 100,000, also similar to that of the cohort (26.3 per 100,000). When separated by sector, the mortality rates in the cohort were similar to or lower than Shanghai women.

There are also some potential limitations of the study, including possible sources of exposure and CVD misclassification. Occupational exposures were approximated by the textile sector of the factory at time of enrollment. This assumes that this factory represents the individual's prior exposure, likely a reasonable assumption given indications there was little mobility between factories. Very few women $(\sim 2 \%)$ changed factories over the followup period and if they did, approximately half of the transfers were within the same textile sector.

The exposure classification did not incorporate other work history factors, such as job type, years worked or process within the factory. While the sector groupings attempted to assess the most common exposures in their respective groups, there was some overlap between them, particularly for particulate exposures. The slight increased risk observed for particulate matter and hemorrhagic stroke was not apparent when restricted to sectors with high non-cotton dusts. This could be due to the smaller numbers in these sectors since the cotton sector is such a large group, or possibly that the endotoxin or other exposure in that sector may have contributed to the observed association. The current analysis was only able to examine endotoxin exposure in detail for a limited number of stroke deaths that were in 
the available subcohort. Nonetheless, to our knowledge, this is the first study able to examine quantitative occupational endotoxin exposure information and CVD mortality.

It is possible there was some misclassification of cause of death as the codes were not validated. However, a study of cities in urban China, including Shanghai, found that sensitivity between death registries and diagnoses was reasonable for ischemic heart disease (69\%) and cerebrovascular disease (82\%) [Rao, et al. 2007]. Use of brain imaging for diagnostic evaluation was likely infrequent in China at the beginning of the study, and much more frequent in later years, as indicated by a recent Chinese report [Zhang, et al. 2003]. As a result, some stroke subtypes may have been misclassified since hemorrhagic strokes are more likely to be fatal than ischemic strokes.

Another limitation of this analysis is unknown confounding by other CVD risk factors such as blood cholesterol levels, coagulation factors, hypertension, other lipids, diabetes, and obesity. It is possible that some of these risk factors could be occupationally influenced intermediates on the causal pathway for CVD, in which case statistical adjustment in the analysis would not be appropriate. Family history of CVD was also unavailable, but is unlikely to have been associated with any occupational exposures considered. Other unmeasured environmental factors could also potentially contribute to risk of CVD, such as ambient air pollution, passive smoking and other sources of particulates, such as those resulting from cooking fuel[Wang, et al. 2009]. However, it is unlikely that these factors varied systematically by industry sector or exposure so as to have produced appreciable confounding.

This study is one of a few large-scale studies of women examining associations between cardiovascular disease mortality and occupational exposures. The findings suggest that exposures in cotton textile factories may contribute to CVD mortality. Corroboration of our findings from other studies of textile workers will be needed to strengthen causal inference. With increasing numbers of women in the industrialized work force and CVD as a leading cause of death, it is increasingly important to understand the influence of occupational exposures on CVD in women.

\section{Acknowledgments}

We thank Wen Wan Wang, the Shanghai study manager, industrial hygienists and Shanghai field workers for their extensive efforts in collecting factory information and personnel records. We also acknowledge George Astrakianakis, Noah Seixas, Janice Camp, Karen Wernli, and Dawn Fitzgibbons for their work on the exposure assessment.

Grant sponsor: The National Cancer Institute at the National Institutes of Health; Grant number: R01CA80180

\section{References}

Astrakianakis G, Seixas N, Camp J, Smith TJ, Bartlett K, Checkoway H. Cotton dust and endotoxin levels in three Shanghai textile factories: a comparison of samplers. J Occup Environ Hyg. 2006; 3:418-427. [PubMed: 16862712]

Astrakianakis G, Seixas NS, Camp JE, Christiani DC, Feng Z, Thomas DB, Checkoway H. Modeling, estimation and validation of cotton dust and endotoxin exposures in Chinese textile operations. Annals of Occupational Hygiene. 2006; 50:573-582. [PubMed: 16632488]

Berry G, Molyneux MK. A mortality study of workers in Lancashire cotton mills. Chest. 1981; 79

Bhatnagar A. Environmental cardiology: studying mechanistic links between pollution and heart disease. Circulation research. 2006; 99:692-705. [PubMed: 17008598]

Bonow RO, Smaha LA, Smith SC Jr. Mensah GA, Lenfant C. World Heart Day 2002: the international burden of cardiovascular disease: responding to the emerging global epidemic. Circulation. 2002; 106:1602-1605. [PubMed: 12270848] 
Brook RD, Rajagopalan S, Pope CA 3rd, Brook JR, Bhatnagar A, Diez-Roux AV, Holguin F, Hong Y, Luepker RV, Mittleman MA, Peters A, Siscovick D, Smith SC Jr. Whitsel L, Kaufman JD.

Particulate matter air pollution and cardiovascular disease: An update to the scientific statement from the American Heart Association. Circulation. 2010; 121:2331-2378. [PubMed: 20458016]

Brown DL, Feskanich D, Sanchez BN, Rexrode KM, Schernhammer ES, Lisabeth LD. Rotating night shift work and the risk of ischemic stroke. American Journal of Epidemiology. 2009; 169:13701377. [PubMed: 19357324]

Chen B, Hong C, Kan H. Exposures and health outcomes from outdoor air pollutants in China. Toxicology. 2004; 198:291-300. [PubMed: 15138055]

Christiani DC, Wegman DH, Eisen EA, Ye TT, Lu PL, Olenchock SA. Cotton dust and gram-negative bacterial endotoxin correlations in two cotton textile mills. Am J Ind Med. 1993; 23:333-342. [PubMed: 8427261]

Christiani DC, Ye TT, Zhang S, Wegman DH, Eisen EA, Ryan LA, Olenchock SA, Pothier L, Dai HL. Cotton dust and endotoxin exposure and long-term decline in lung function: results of a longitudinal study. Am J Ind Med. 1999; 35:321-331. [PubMed: 10086207]

Dockery DW, Pope CA, Xu X, Spengler JD, Ware JH, Fay ME, Ferris BG, Speizer FE. An Association between Air Pollution and Mortality in Six U.S. Cities. New England Journal of Medicine. 1993; 329:1753-1759. [PubMed: 8179653]

Fleming LE, Gomez-Marin O, Zheng D, Ma F, Lee D. National Health Interview Survey mortality among US farmers and pesticide applicators. Am J Ind Med. 2003; 43:227-233. [PubMed: 12541279]

Fritschi L, Lakhani R, Nadon L, Bulsara M. Mortality in an Australian cohort of textile workers. Occupational Medicine. 2004; 54:255-257. [PubMed: 15190163]

Gelbke HP, Goen T, Maurer M, Sulsky SI. A review of health effects of carbon disulfide in viscose industry and a proposal for an occupational exposure limit. Crit Rev Toxicol. 2009; 39(Suppl 2):1126. [PubMed: 19852562]

Health Effects Institute. Reanalysis of the Harvard Six Cities Study and the American Cancer Society study of particulate air pollution and mortality : a special report of the Institute's Particle Epidemiology Reanalysis Project Cambridge, Mass. Health Effects Institute; 955 Mass. Ave., Cambridge: 2000.

Hodgson JT, Jones RD. Mortality of workers in the British cotton industry in 1968-1984. Scandinavian journal of work, environment \& health. 1990; 16:113-120.

Kane, P.; Dennerstein, L.; World Health O. Women and occupational health : issues and policy paper for the Global Commission on Women's Health. World Health Organization; Geneva: 1999.

Kawachi I, Colditz GA, Stampfer MJ, Willett WC, Manson JE, Speizer FE, Hennekens CH. Prospective study of shift work and risk of coronary heart disease in women. Circulation. 1995; 92:3178-3182. [PubMed: 7586301]

Kennedy SM, Christiani DC, Eisen EA, Wegman DH, Greaves IA, Olenchock SA, Ye TT, Lu PL. Cotton dust and endotoxin exposure-response relationships in cotton textile workers. Am Rev Respir Dis. 1987; 135:194-200. [PubMed: 3800146]

Koskela RS, Klockars M, Järvinen E. Mortality and disability among cotton mill workers. British journal of industrial medicine. 1990; 47:384-391. [PubMed: 2143077]

Kristensen TS. Cardiovascular diseases and the work environment. A critical review of the epidemiologic literature on nonchemical factors. Scandinavian journal of work, environment \& health. 1989; 15:165-179.

Lee E, Burnett CA, Lalich N, Cameron LL, Sestito JP. Proportionate mortality of crop and livestock farmers in the United States, 1984-1993. American Journal of Industrial Medicine. 2002; 42:410 420. [PubMed: 12382254]

Merchant JA, Ortmeyer C. Mortality of employees of two cotton mills in North Carolina. Chest. 1981; 79

Miller KA, Siscovick DS, Sheppard L, Shepherd K, Sullivan JH, Anderson GL, Kaufman JD. LongTerm Exposure to Air Pollution and Incidence of Cardiovascular Events in Women. New England Journal of Medicine. 2007; 356:447-458. [PubMed: 17267905] 
Olenchock SA, Christiani DC, Mull JC, Ye TT, Lu PL. Endotoxins in baled cottons and airborne dusts in textile mills in the People's Republic of China. Appl Environ Microbiol. 1983; 46:817-820. [PubMed: 6639029]

Parkin, D.; Whelan, SL.; Ferlay, J.; Rayond, L.; Young, J., editors. Cancer incidence in five continents. International Agency for Research on Cancer; Lyon: 1997.

Price AE. Heart disease and work. Heart. 2004; 90:1077-1084. [PubMed: 15310715]

Rao C, Yang G, Hu J, Ma J, Xia W, Lopez AD. Validation of cause-of-death statistics in urban China. International Journal of Epidemiology. 2007; 36:642-651. [PubMed: 17329316]

Sjogren B, Lonn M, Feychting M, Nise G, Kauppinen T, Plato N, Wiebert P, Gustavsson P. Occupational exposure to particles and incidence of stroke. Scand J Work Environ Health. 2012

Sjögren B, Weiner J. Mortality from ischaemic heart disease in textile workers. Occupational and Environmental Medicine. 2011; 68:706. [PubMed: 21676950]

Sjögren B, Weiner J, Larsson K. Ischaemic heart disease among livestock and agricultural workers. Occup Environ Med. 2003; 60:e1. [PubMed: 12883028]

Steenland, K.; Fine, L.; Belkic, K.; Landsbergis, P.; Schnall, P.; Baker, D.; Theorell, T.; Siegrist, J.; Peter, R.; Karasek, R.; Marmot, M.; Brisson, C.; Tüchsen, F. Occupational medicine. Vol. 15. Philadelphia, $\mathrm{Pa} .:$ 2000. Research findings linking workplace factors to CVD outcomes..

Stoll LL, Denning GM, Weintraub NL. Potential role of endotoxin as a proinflammatory mediator of atherosclerosis. Arteriosclerosis, thrombosis, and vascular biology. 2004; 24:2227-2236.

Su W-L, Chen Y-H, Liou S-H, Wu C-P. Meta-Analysis of Standard Mortality Ratio in Cotton Textile Workers. European Journal of Epidemiology. 2004; 19:989-997. [PubMed: 15648591]

Thomas DB, Gao DL, Ray RM, Wang WW, Allison CJ, Chen FL, Porter P, Hu YW, Zhao GL, Pan LD, Li W, Wu C, Coriaty Z, Evans I, Lin MG, Stalsberg H, Self SG. Randomized Trial of Breast Self-Examination in Shanghai: Final Results. Journal of the National Cancer Institute. 2002; 94:1445. [PubMed: 12359854]

Thomas DB, Gao DL, Self SG, Allison CJ, Tao Y, Mahloch J, Ray R, Qin Q, Presley R, Porter P. Randomized Trial of Breast Self-examination in Shanghai: Methodology and Preliminary Results. Journal of the National Cancer Institute. 1997; 89:355. [PubMed: 9060957]

Tuchsen F, Bach E, Marmot M. Occupation and hospitalization with ischaemic heart diseases: a new nationwide surveillance system based on hospital admissions. Int J Epidemiol. 1992; 21:450-459. [PubMed: 1634305]

Ueshima H, Sekikawa A, Miura K, Turin TC, Takashima N, Kita Y, Watanabe M, Kadota A, Okuda N, Kadowaki T, Nakamura Y, Okamura T. Cardiovascular disease and risk factors in Asia: a selected review. Circulation. 2008; 118:2702-2709. [PubMed: 19106393]

Wang XR, Chiu YL, Qiu H, Au JS, Yu IT. The roles of smoking and cooking emissions in lung cancer risk among Chinese women in Hong Kong. Ann Oncol. 2009; 20:746-751. [PubMed: 19150939]

Waterhouse, J.; Muir, CS.; Correa, P.; Powell, J. Cancer incidence in five continents : Volume III. International Agency for Research on Cancer; Lyon: 1976.

Wernli KJ, Astrakianakis G, Camp JE, Ray RM, Chang CK, Li GD, Thomas DB, Checkoway H, Seixas NS. Development of a job exposure matrix (JEM) for the textile industry in Shanghai, China. J Occup Environ Hyg. 2006; 3:521-529. [PubMed: 16908453]

Wu Z, Yao C, Zhao D, Wu G, Wang W, Liu J, Zeng Z, Wu Y. Sino-MONICA project: a collaborative study on trends and determinants in cardiovascular diseases in China, Part i: morbidity and mortality monitoring. Circulation. 2001; 103:462-468. [PubMed: 11157701]

Zanardi F, Harris EC, Brown T, Rice S, Palmer KT, Coggon D. Mortality from diabetes and ischaemic heart disease in textile workers. Occupational and Environmental Medicine. 2011; 68:172-175. [PubMed: 20798003]

Zhang LF, Yang J, Hong Z, Yuan GG, Zhou BF, Zhao LC, Huang YN, Chen J, Wu YF. Proportion of different subtypes of stroke in China. Stroke. 2003; 34:2091-2096. [PubMed: 12907817] 


\section{Table I}

Distribution of Selected Lifestyle, Reproductive and Occupational Characteristics of Female Textile Workers in Shanghai, China, 1989-1991

\begin{tabular}{llrr}
\hline Characteristic & & No. of Women $(\mathbf{N}=\mathbf{2 6 7 , 4 0 0})$ & $(\boldsymbol{\%})$ \\
\hline Age group at study entry & $30-39$ yrs & 106,855 & 40.0 \\
& $40-49$ yrs & 51,527 & 19.3 \\
& $50-59$ yrs & 65,385 & 24.5 \\
& $60+$ yrs & 43,633 & 16.3 \\
Smoking history & never & 259,494 & 97.0 \\
Textile Sector & ever & 7,868 & 2.9 \\
& Assembly and sewing & 18,495 & 6.9 \\
& Bleaching/dyeing/printing & 21,424 & 8.0 \\
& Combined & 39,408 & 14.7 \\
& Cotton SWK & 86,265 & 32.3 \\
& Machine manufacturing & 17,275 & 6.5 \\
& Mixed fiber SWK & 26,262 & 9.8 \\
& Other services & 6,634 & 2.5 \\
& Silk SWK & 11,121 & 4.2 \\
& Synthetic SWK & 11,335 & 4.2 \\
& Wool SWK & 29,181 & 10.9 \\
\hline
\end{tabular}

Textile sector based on factory at baseline

SWK=Spinning, weaving and knitting 


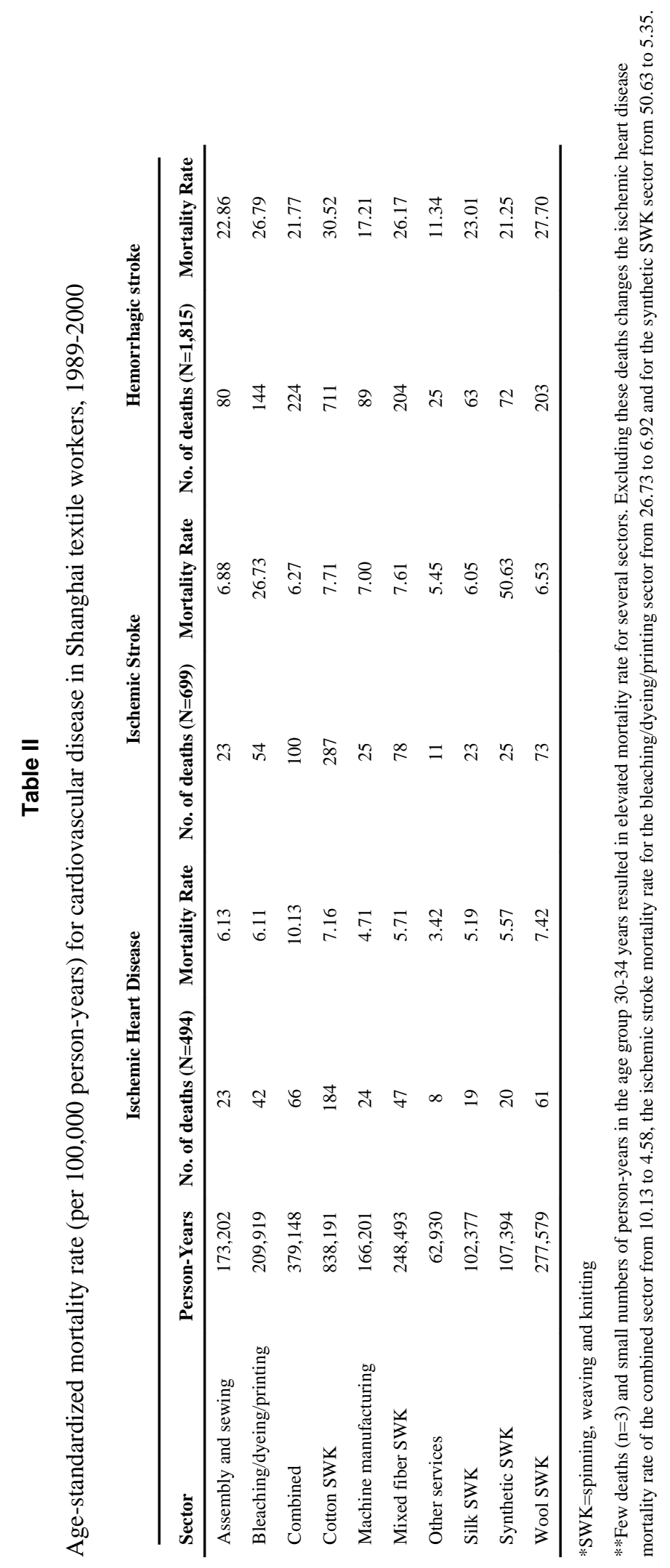

Am J Ind Med. Author manuscript; available in PMC 2013 November 01. 


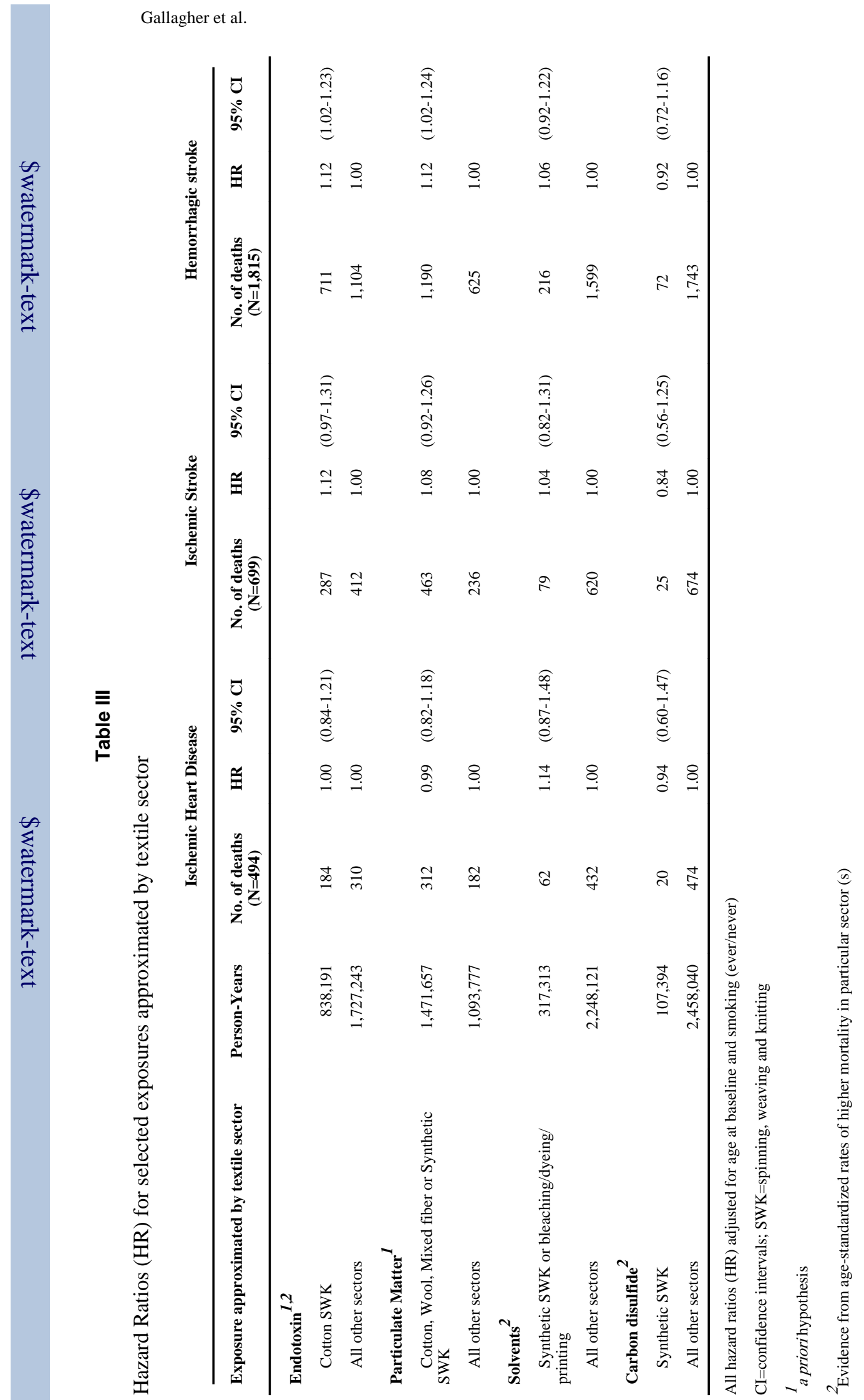

Page 13 


\section{Table IV}

Hazard Ratios (HR) for stroke mortality and estimated cumulative exposure to endotoxin and cotton dust

\begin{tabular}{|c|c|c|c|c|}
\hline Exposure variable & No. of Deaths $(N=60)$ & No. of Subcohort $(\mathrm{N}=3,128)$ & HR & $95 \% \mathrm{CI}$ \\
\hline \multicolumn{5}{|c|}{$\operatorname{Endotoxin}\left(\mathbf{E} \mathbf{U}^{\S} / \mathbf{m}^{3} \times\right.$ year $)$} \\
\hline Unexposed & 20 & 891 & 1.00 & referent \\
\hline$>0-2275.08$ & 10 & 960 & 0.71 & $(0.33-1.53)$ \\
\hline$>2275.08-2943.66$ & 10 & 364 & 1.07 & $(0.49-2.32)$ \\
\hline$>2943.66-5167.85$ & 10 & 470 & 0.91 & $(0.43-1.95)$ \\
\hline$>5167.85$ & 10 & 280 & 1.52 & $(0.72-3.24)$ \\
\hline$P$ for trend ${ }^{t}$ & & & 0.09 & \\
\hline \multicolumn{5}{|c|}{ Cotton Dust $\left(\mathrm{mg} / \mathrm{m}^{3} \times\right.$ year $)$} \\
\hline Unexposed & 20 & 991 & 1.00 & referent \\
\hline$>0-85.64$ & 10 & 936 & 0.75 & $(0.35-1.61)$ \\
\hline$>85.64-118.06$ & 10 & 413 & 1.12 & $(0.52-2.41)$ \\
\hline$>118.06-175.94$ & 10 & 427 & 1.14 & $(0.53-2.48)$ \\
\hline$>175.94$ & 10 & 347 & 1.15 & $(0.54-2.42)$ \\
\hline$P$ for trend ${ }^{t}$ & & & 0.35 & \\
\hline
\end{tabular}

All hazard ratios (HR) adjusted for age at baseline and smoking (ever/never)

$\mathrm{CI}=$ confidence interval

Women who died from ischemic heart disease in the subcohort were excluded from quantitative analyses of endotoxin and cotton dust ( $\mathrm{n}=13$ ). Women who were ever employed as machinists, in sanitation, or in wool production were excluded from quantitative analyses of endotoxin $(\mathrm{n}=149)$.

${ }^{t}$ Trend tests across median of each category, among exposed only

$\mathcal{\xi}_{\text {EU, endotoxin units }}$ 